\title{
Type II cGMP-dependent protein kinase inhibits EGF-triggered signal transduction of the MAPK/ ERK-mediated pathway in gastric cancer cells
}

\author{
YAN WU, YONGCHANG CHEN, RUI QU, TING LAN and JIANRONG SANG \\ School of Medical Science and Medical Technology, Jiangsu University, Zhenjiang, Jiangsu 212013, P.R. China
}

Received August 30, 2011; Accepted September 23, 2011

DOI: $10.3892 /$ or.2011.1507

\begin{abstract}
Our previous study found that Type II cGMPdependent protein kinase (PKG II) is expressed at lower levels in human gastric cancer tissues and cell lines and increasing the expression and activity of PKG II inhibited the proliferation of cancer cell line BGC-823. However, the mechanism through which PKG II inhibits proliferation of gastric cancer cells is still not clear. Herein, we show that PKG II can inhibit EGF-induced MAPK signal transduction. In the gastric cancer cell line BGC-823, the expression and activity of PKG II were increased by infecting the cells with adenoviral construct encoding PKG II cDNA and treating the cells with the cGMP analogue 8-pCPTcGMP. We found that PKG II inhibited the EGF-induced dual phosphorylation of ERK, a key component of the MAPK signal transduction pathway. Upstream of ERK, PKG II inhibited the phosphorylation of MEK1/2, the phosphorylation/activation of Raf-1, the activation of Ras, and the binding between adaptor protein Grb2 and GTP exchange factor Sos1 induced by EGF. Of note, PKG II inhibited the tyrosine phosphorylation of EGFR induced by EGF. Downstream of ERK, the EGF-induced nuclear translocation of phospho-ERK was also inhibited by PKG II. The results suggest that PKG II inhibits the proliferation of gastric cancer cells through blocking EGF-triggered MAPK signal transduction and the key blocking point is the tyrosine phosphorylation of the EGF receptor.
\end{abstract}

\section{Introduction}

cGMP-dependent protein kinases (PKGs) are serine/threonine kinases and currently two types of PKGs, PKG I and PKG II, have been identified in mammals $(1,2)$. PKG I is widely distributed within the body and its expression is reduced in

Correspondence to: Dr Yongchang Chen, \#301 Xuefu Road, School of Medical Science and Medical Technology, Jiangsu University, Zhenjiang City, Jiangsu Province 212013, P.R. China

E-mail: ycchen54@ujs.edu.cn

Key words: type II cGMP-dependent protein kinase, EGF, MAPK, signal transduction, gastric cancer cells many tumor tissues compared to respective normal tissue. Exogenous PKG I leads to decreased tumor growth and invasiveness in many cells including cardiomyocytes, mesangial cells, pancreatic $\beta$-cell line, and neutrophils (3-6). PKG I also has a role in inducing apoptosis in colon tumor cells treated with the phosphodiesterase inhibitor exisulind $(7,8)$. PKG I has been identified as a tumor suppressor (9). Unlike PKG I, the expression of PKG II is more tissue-restricted (10). As a structurally and functionally distinct membrane-bound enzyme $(11,12)$, PKG II has been implicated in several physiological functions including intestinal secretion, bone growth, and learning and memory (13). For a long time, in contrast to the well-proven anti-tumor effect of PKG I, no research data clearly indicated antitumor role of PKG II. However, recent research results did suggest that PKG II had a role in regulating cell proliferation and apoptosis (14-17). More importantly, in 2010, Swartling et al reported that PKG II inhibited the proliferation of human neuroglioma cells and the inhibition was related to the decrease of the expression of transcription factor Sox 9 and the phosphorylation of Akt (18). In the same year, we found that the expression and the activity of PKG II in human gastric cancer cell lines were significantly lower than that in normal cells (19). Also, further study in our laboratory showed that PKG II inhibited the proliferation of gastric cancer cell lines (20). To explore the mechanism of the tumor-inhibitory action of PKG II, this study was designed to elucidate the possible inhibition of PKG II on proliferation related MAPK-mediated signal transduction.

\section{Materials and methods}

Cell lines and reagents. Human gastric cancer cell line BGC-823 was provided by the Institute of Cell Biology (Shanghai, China). Adenoviral vectors encoding the cDNA $\beta$-galactosidase (pAd-LacZ) and PKG II (pAd-PKG II) were kind gifts from Dr Gerry Boss and Dr Renate Pilz, University of California, San Diego, CA, USA. Dulbecco's modified Eagle's medium (DMEM) and newborn calf serum (NBCS) were from Gibco (Grand Island, NY). The antibody against PKG II was from Abgent Biotechnology (San Diego, CA). Goat anti- $\beta$-action, mouse anti-Pan-Ras, rabbit anti-p-Raf-1 (Ser 338/Tyr 341), rabbit anti-Grb2, and mouse anti-Sos1 antibodies were from Santa Cruz Biotechnology (Santa Cruz, 
CA). Mouse anti-p-EGFR (Tyr 1068), rabbit anti-EGFR, rabbit anti-p-MEK1/2 (Ser 217/221), rabbit anti-p-ERK threonine 202 and tyrosine 204 (Thr 202/Tyr 204), and rabbit anti-ERK antibodies were from Cell Signaling Technology (Danvers, MA). Rabbit anti-MEK1/2 was from Bioworld Technology (St. Louis Park, MN). The horseradish peroxidase (HRP)-conjugated secondary antibodies were from Jackson ImmunoResearch Laboratories (West Grove, PA). The cellular permeable cGMP analog 8-pCPT-cGMP was from Calbiochem (San Diego, CA). EGF and fluorochrome Cy3, FITC and Hoechst 33342 were from Sigma (St. Louis, MO). Electrochemiluminescence (ECL) reagents were from Millipore (Billerica, MA). ${ }^{3} \mathrm{H}$-labeled thymidine was from PerkinElmer (San Jose, CA). All other reagents used were of analytical grade.

Cell culture and infection with adenoviral vectors. BGC-823 cells were cultured in DMEM supplied with 10\% NBCS and maintained at $37^{\circ} \mathrm{C}$ in a humidified incubator with $95 \%$ air and $5 \% \mathrm{CO}_{2}$. The medium was changed every two days and the cells were sub-cultured at confluence. On the day before infection with adenovirus, cells were freshly planted at $70-80 \%$ confluence, and infection was performed as reported previously (21).

${ }^{3} \mathrm{H}$-thymidine uptake assay. Cells were seeded at density of $0.8 \times 10^{5}$ cells per well in a 12 -well plate in DMEM $+10 \%$ NBCS. Next day, the cells were infected with pAd-LacZ or pAd-PKG II. On the third day, the cells were serum-starved for $24 \mathrm{~h}$. On the fourth day, the cells were stimulated with EGF $(100 \mathrm{ng} / \mathrm{ml})$ for $12 \mathrm{~h}$ and labeled with $\left[{ }^{3} \mathrm{H}\right]$-thymidine $(1 \mu \mathrm{ci})$ for $8 \mathrm{~h}$. The cells were washed with cold PBS and lysed at room temperature by adding $0.5 \mathrm{ml} 0.5 \mathrm{~N} \mathrm{NaOH} / 0.5 \%$ SDS and pipetting up and down several times. The lysate was diluted with $0.5 \mathrm{ml}$ of ice cold $20 \%$ TCA and incubated at $4{ }^{\circ} \mathrm{C}$ for $30 \mathrm{~min}$. The DNA in the lysate was collected on glass fiber filter. The filter was dried at $50^{\circ} \mathrm{C}$ and put in scintillation vials. The CPM was counted with a scintillation counter.

Nuclear protein preparation. According to the method of Chen et al (22), cells growing on 100-mm plates were harvested in HEM buffer (10 mM HEPES pH 7.5, 2 mM EDTA, $1 \mathrm{mM}$ $\mathrm{MgCl}_{2}$ ) and homogenized with an ultrasonic homogenizer. The homogenate was centrifuged at $500 \mathrm{xg}$ at $4^{\circ} \mathrm{C}$ for $5 \mathrm{~min}$ to obtain nuclei of the cells. Pre-heated SDS-PAGE loading buffer was added to the pellet and boiled for $5 \mathrm{~min}$ to get nuclear proteins.

Western blotting. Proteins from whole-cell and nuclear extracts were separated by $10 \%$ SDS-PAGE. The primary antibodies were incubated overnight at $4{ }^{\circ} \mathrm{C}$, and the corresponding secondary antibodies were incubated for $1 \mathrm{~h}$ at RT, with three washes after each incubation. ECL reagents were used to show the positive bands on the membrane.

Ras activity assay. The assay was performed as described previously with some modification (23). Briefly, cells at $\sim 90 \%$ confluence on 100 -mm culture plates were washed three times with cold PBS and lysed in lysis buffer containing $25 \mathrm{mM}$ HEPES (pH 7.5), $150 \mathrm{mM} \mathrm{NaCl}, 1 \% \mathrm{NP} 40,10 \%$ glycerol, $25 \mathrm{mM} \mathrm{NaF}, 10 \mathrm{mM} \mathrm{MgCl}, 2.25 \%$ sodium deoxycholate,

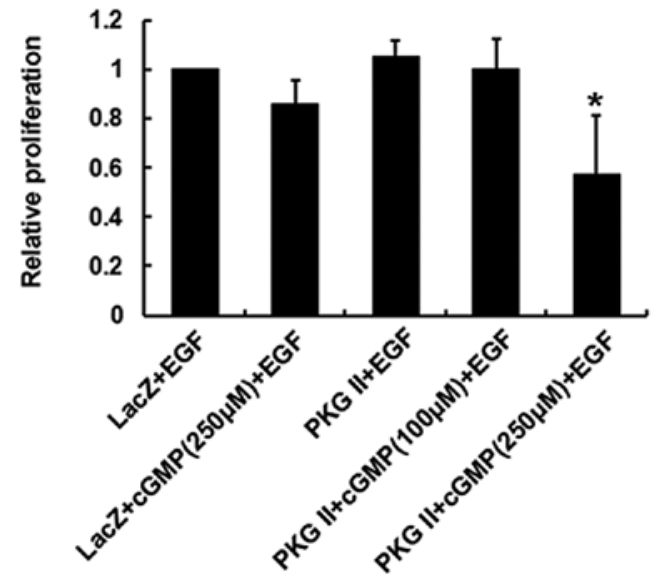

Figure 1. PKG II inhibits the thymidine uptake by BGC-823 cells. Either pAd-PKG II-infected or pAd-LacZ-infected cells growing in a 12-well plate were serum-starved for $12 \mathrm{~h}$, stimulated with 8-pCPT-cGMP (100 $\mu \mathrm{M}$ and $250 \mu \mathrm{M})$ for $1 \mathrm{~h}$, and then incubated with EGF $(100 \mathrm{ng} / \mathrm{ml})$ for $12 \mathrm{~h}$. Cell proliferation was assessed by the ${ }^{3} \mathrm{H}$-thymidine uptake assay as described in Materials and methods. The data shown are the means \pm SD from three independent experiments, each performed in duplicate $\left({ }^{*} \mathrm{P}<0.05\right.$, compared to LacZ + EGF group, LacZ + cGMP + EGF group and PKG II+ EGF group).

$1 \mathrm{mM}$ EDTA, $1 \mathrm{mM} \mathrm{Na}_{3} \mathrm{VO}_{4}, 10 \mu \mathrm{g} / \mathrm{ml}$ aprotinin and $10 \mu \mathrm{g} / \mathrm{ml}$ leupeptin. After a centrifugation to get rid of the debris, the cell lysate was incubated with glutathione-Sepharose beads and glutathione S-transferase-Ras-RBD (GST-RBD) at $4^{\circ} \mathrm{C}$ for $1 \mathrm{~h}$. The beads were washed three times with lysis buffer. The GTP-bound Ras was eluted by adding SDS-PAGE loading buffer and boiling for $5 \mathrm{~min}$ and detected by Western blotting with antibody against Pan-Ras.

Co-immunoprecipitation. The binding between Grb2 and Sos1 was detected by Co-immunoprecipitation. Cells were lysed with RIPA buffer (50 mM Tris-HCl pH 7.4, 1\% Triton X-100, $1 \mathrm{mM}$ EDTA, $1 \mathrm{mM}$ leupeptin, $1 \mathrm{mM}$ phenylmethylsulfonyl fluoride, $10 \mathrm{mM} \mathrm{NaF}, 1 \mathrm{mM} \mathrm{Na} \mathrm{VO}_{4}$ ). Antibodies against Grb2 and Sos1 and isotype matched $\operatorname{IgG}$ were used for immunoprecipitation and immunoblotting assay.

Immunofluorescence microscopy. The cells growing on cover slips were fixed with freshly prepared $40 \mathrm{~g} / \mathrm{l}$ paraformaldehyde in PBS for $15 \mathrm{~min}$, permeabilized with $0.3 \%$ Triton X-100 in PBS for 10 min, and blocked with 3\% BSA in PBS. The cells on cover slips were subsequently incubated with mouse polyclonal antibody against p-ERK for $2 \mathrm{~h}$ at RT, followed by incubation with Cy3-conjugated goat anti-mouse IgG for $1 \mathrm{~h}$ at RT, and washed three times after each incubation. The nuclei were stained with Hoechst 33342. The distribution of p-ERK in the cells was viewed under a fluorescent microscope.

Statistical analysis. The data were expressed as the means \pm standard deviation (SD). Statistical significance was performed using ANOVA with SPSS statistical software. $\mathrm{P}<0.05$ was considered significant.

\section{Results}

PKG II inhibits the thymidine uptake by BGC-823 cells. Our previous investigations applied several methods to study the 
A

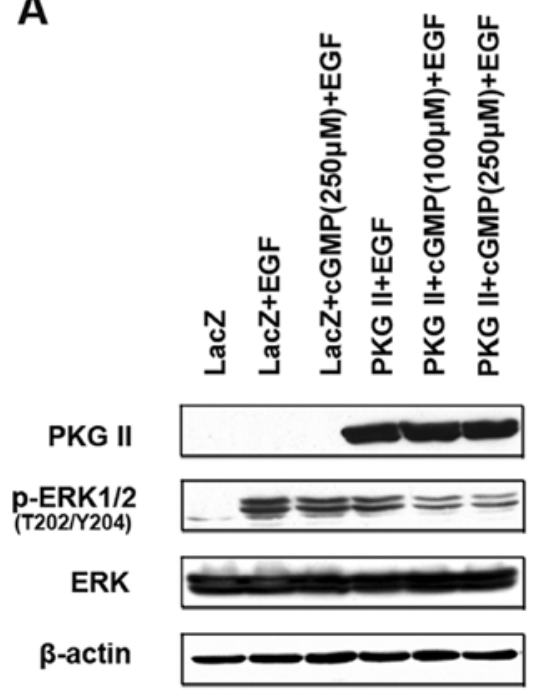

B

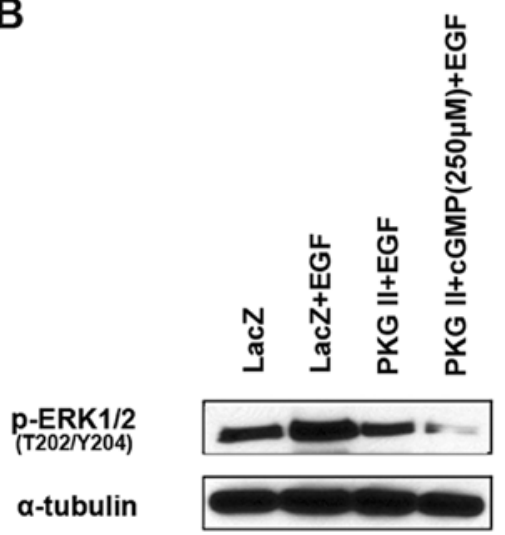

C

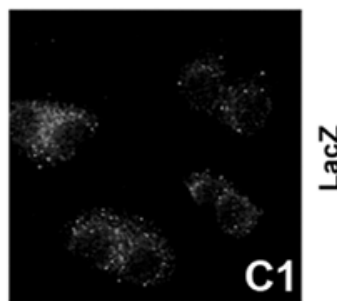

Nู
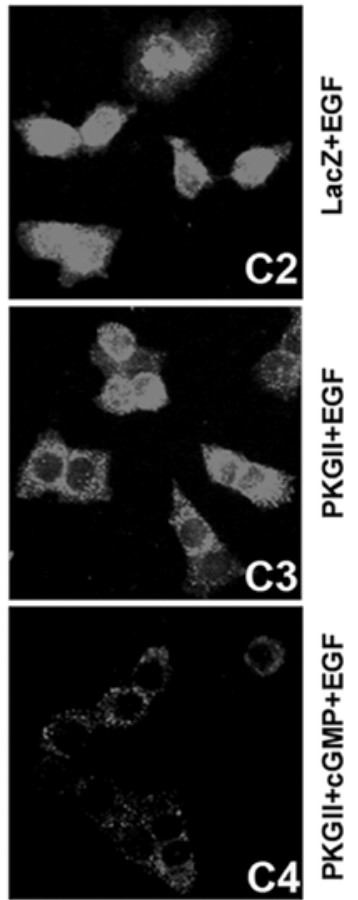

Figure 2. PKG II blocks the dual phosphorylation of ERK and the nuclear translocation of p-ERK. (A) The results of Western blotting detecting PKG II expression and the phosphorylation of ERK1/2 (Thr 202/Tyr 204). BGC-823 cells were infected with either pAd-LacZ or pAd-PKG II, serum-starved for $12 \mathrm{~h}$, stimulated with 8-pCPT-cGMP $(100$ and $250 \mu \mathrm{M})$ for $1 \mathrm{~h}$, and then treated with EGF $(100 \mathrm{ng} / \mathrm{ml})$ for 5 min. The cell lysate was analyzed by Western blotting with the anti-ERK or anti-p-ERK antibodies. The results showed that $5 \mathrm{~min}$ after adding EGF to culture medium, the phosphorylation of ERK1/2 increased dramatically. The treatment of infecting with pAd-PKG II and stimulating with 8-pCPT-cGMP inhibited the phosphorylation. (B) The distribution of p-ERK1/2 in nuclei of BGC-823 cells. The cells were lysed and the nuclear proteins were obtained. Western blotting with indicated antibodies was used to analyze the amount of p-ERK1/2 in nuclei of BGC-823 cells. It showed that the high expression and activity of PKG II significantly inhibited the EGF-induced increase of nuclear p-ERK. (C) Representative images of immunofluorescence staining of p-ERK1/2. BGC-823 cells treated as in (B) were fixed with $40 \mathrm{~g} / 1$ paraformaldehyde and stained for $\mathrm{p}$-ERK1/2. The results show the localization of $\mathrm{p}$-ERK in nucleus and the blockage of nuclear translocation of $\mathrm{p}$-ERK by high expression and activation of PKG II; (x200).

proliferation-inhibition effect of PKG II, including MTT assay, analysis of anchorage-independent growth, tumor formation in nude mice, detection of PCNA, and BrdU uptake assay. In this study, we applied the thymidine uptake assay to further confirm the inhibitory effect of PKG II on proliferation of the gastric cancer cells. BGC-823 cells were infected with pAdLacZ or pAd-PKG II, treated with 8-pCPT-cGMP and/or EGF, and incubated with ${ }^{3} \mathrm{H}$-labeled thymidine. Liquid scintillation counter was used to count radioactivity of the cells. The results showed that EGF stimulated thymidine uptake of BGC-823 cells and PKG II significantly inhibited the proliferationstimulating action of EGF (Fig. 1).

PKG II blocks the dual phosphorylation of ERK and the nuclear translocation of activated ERK. Phosphorylation at both Thr 202/Tyr 204 residues of ERK1 and Thr 185/Tyr 187 residues of ERK2 is required for full enzymatic activation. The antibody against p-ERK1/2 (Thr 202/Tyr 204) was applied in Western blotting to detect the dual phosphorylation of ERK. The results showed that within 5 min after adding EGF (100 $\mathrm{ng} / \mathrm{ml})$ to culture medium, phosphorylation of ERK1/2 increased dramatically and the phosphorylation was inhibited by pre-infecting the cells with pAd-PKG II and stimulating the enzyme with 8-pCPT-cGMP (Fig. 2A). Moreover, the high expression and activity of PKG II significantly inhibited the EGF-induced nuclear translocation of p-ERK (Fig. 2B and C).

PKG II suppresses the phosphorylation of MEK. MEK1 and MEK2 are members of the dual specificity protein kinase family, which acts as a MAPK or ERK kinase. Activation of MEK1/2 occurs through phosphorylation of two serine residues at positions 217 and 221 by Raf-like molecules. In this study, the antibody against p-MEK1/2 (Ser 217/221) was used to detect the phosphorylation of MEK1/2. The results revealed that EGF (100 ng/ml) treatment caused obvious phosphorylation of MEK1/2, while the high expression and activity of 

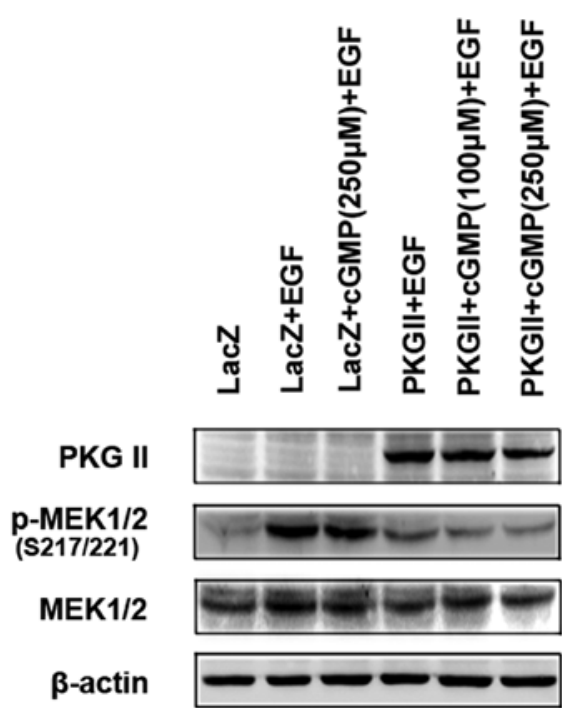

Figure 3. PKG II suppresses the phosphorylation of MEK. BGC-823 cells were infected as indicated, serum-starved overnight, stimulated with 8-pCPTcGMP (100 and $250 \mu \mathrm{M})$ for $1 \mathrm{~h}$, and treated with EGF $(100 \mathrm{ng} / \mathrm{ml})$ for $5 \mathrm{~min}$. The equal protein extracts were immunoblotted for phospho-MEK1/2, PKG II, total MEK1/2 and $\beta$-actin (indicating loading control). The results show that 5 min after adding EGF to culture medium, the phosphorylation of MEK1/2 increased dramatically. The high expression and activity of PKG II significantly inhibited the EGF-induced phosphorylation of MEK1/2 at Ser 217/221. The results shown are representative of three separate experiments.

PKG II significantly suppressed the MEK1/2 phosphorylation at Ser 217 and 221 caused by EGF treatment (Fig. 3).

PKG II inhibits the activation of Raf-1 and Ras. Raf-1 is a regulator upstream of ERK in MAPK-mediated signal pathway. When it is phosphorylated at Ser 338/339 and Tyr 340/341, Raf-1 is activated and can induce the phosphorylation/activation of MEK, a protein kinase phosphorylating ERK. To investigate the activation of Raf-1, the antibody against p-Raf-1 (Ser 338 and Tyr 341) was applied in Western blotting to detect the phosphorylation of the protein. The results showed that EGF (100 ng/ml) treatment caused an obvious increase of Raf-1 phosphorylation and increased expression and activity of PKG II efficiently inhibited this process (Fig. 4, upper panel).

Small G protein Ras is the key component in MAPKmediated signal pathway. It has two forms in cells: GTP-bound active form and GDP-bound inactive form. Once Ras is in GTP-bound form, it can bind and activate Raf-1 and start the consequent activations of serine/threonine kinase in the signal pathway. We applied 'pull-down' method to isolate and detect the activated Ras. The results showed that after adding EGF (100 $\mathrm{ng} / \mathrm{ml})$ to the culture medium, active Ras increased obviously within $5 \mathrm{~min}$. Infecting the cells with pAd-PKG II and stimulating them with 8-pCPT-cGMP significantly prevented the EGF-induced Ras activation (Fig. 4, lower panel).

PKG II inhibits EGF-induced binding between adaptor protein Grb2 and GEF protein Sos1. Sos1 is a guanine nucleotide exchange factor (GEF). When Sos1 associates with Grb2, it causes the guanine nucleotide exchange of Ras (from GDP-bound to GTP-bound). To investigate the possible effect of PKG II on the binding between Grb2 and Sos1, we applied Co-immunoprecipitation to detect the binding between the
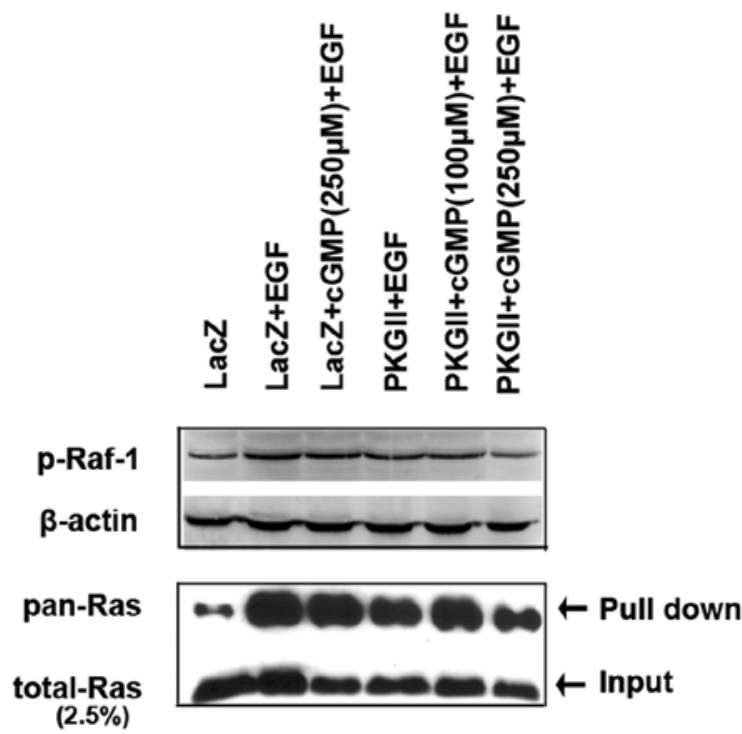

Figure 4. PKG II inhibits the activation of Raf-1 and Ras. (Upper panel) Western blotting is used to detect the phosphorylation of Raf-1 (Ser 338 and Tyr 341). Equal amounts of protein were subjected to SDS-PAGE, and blots were probed with anti-p-Raf-1. The result show that after adding EGF (100 ng/ml) to the culture medium, phosphorylation of Raf-1 increased obviously within $5 \mathrm{~min}$. The EGF-induced Raf-1 phosphorylation was efficiently inhibited in pAd-PKG II-infected and 8-pCPT-cGMP (100 and $250 \mu \mathrm{M}$ )treated cells (compared to pAd-LacZ or pAd-PKG II-infected groups). (Lower panel) The 'pull-down' method was used to detect the activated Ras. Equal amounts of protein were incubated with GST-RBD as described in Materials and methods. Complexes were collected with glutathione-sepharose and resolved by SDS-PAGE, and probed with anti-pan Ras antibody. The results showed that EGF treatment caused an obvious activation of Ras. In the presence of 8 -pCPT-cGMP $(250 \mu \mathrm{M})$, pAd-PKG II-infected cells inhibited Ras activation, while infection with pAd-LacZ or pAd-PKG II alone had no significant inhibitory effect. The results shown are representative of three separate experiments.

proteins. The results showed that treatment with EGF (100 ng/ ml) caused an increase of the binding between Grb2 and Sos1 and the high expression and activity of PKG II blocked the binding (Fig. 5A).

PKG II blocks the tyrosine phosphorylation of EGF receptor. EGFR has several tyrosine-phosphorylation sites. When EGF binds with EGFR, the binding will cause the dimerization and the auto-phosphorylation of tyrosine of the receptors. The phosphorylated tyrosines on EGFR can provide binding sites for adaptor proteins. Among them, phosphorylated Tyr 1068 is related to the activation of MAPK-mediated signal pathway. In this experiment, we applied the antibody against p-EGFR (Tyr 1068) in Western blotting to investigate the possible blocking effect of PKG II on phosphorylation of Tyr 1068 of EGFR. The results showed that EGF $(100 \mathrm{ng} / \mathrm{ml})$ treatment caused obvious Tyr 1068 phosphorylation of EGFR and high expression and activity of PKG II blocked the phosphorylation process (Fig. 5B).

\section{Discussion}

The importance of PKG II has not been fully recognized even though it has been indentified for many years. Recently, some new functions of PKG II were found. For example, Rangaswami et al reported that PKG II had an important role 


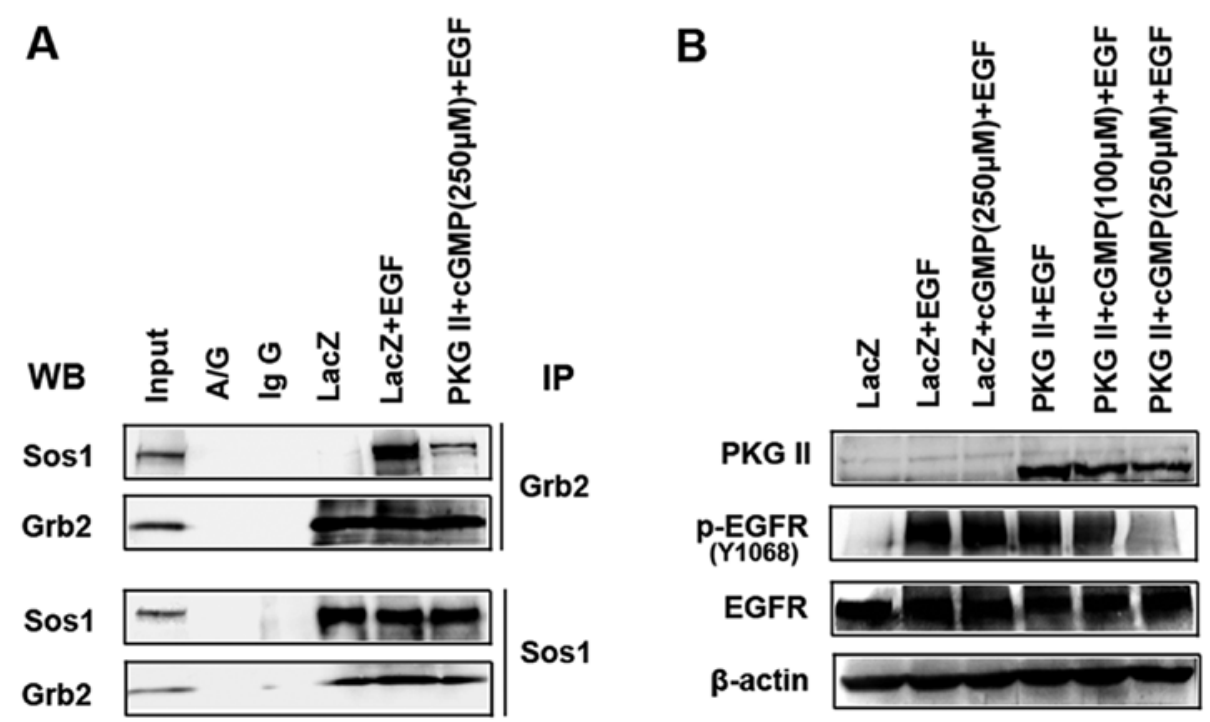

Figure 5. PKG II inhibits the binding between Grb2 and Sos1 and blocks the tyrosine phosphorylation of EGFR. (A) BGC-823 cells were grown in 100-mm plates and infected with either vector or pAd-PKG II. Then, the cells were serum-starved overnight, stimulated with $250 \mu \mathrm{M} \mathrm{8-pCPT-cGMP} \mathrm{for} 1 \mathrm{~h}$ and followed by treatment with EGF (100 ng/ml) for $5 \mathrm{~min}$ as indicated. Co-immunoprecipitation was performed to analyze the effect of PKG II on the binding between Grb2 and Sos1. The experiment included three groups: the pAd-LacZ group, pAd-LacZ + EGF group and pAd-PKG II+ cGMP + EGF group. The results showed that EGF treatment increased the binding between Grb2 and Sos1 and high expression and activity of PKG II significantly inhibited the binding. (B) Western blotting was applied to investigate the effect of PKG II on Tyr 1068 phosphorylation of EGFR. The results revealed that the Tyr 1068 phosphorylation of EGFR was induced by EGF, and the phosphorylation process was obviously blocked in pAd-PKG II-infected and 8-pCPT-cGMP (100 and $250 \mu \mathrm{M}$ )-treated cells. The results shown are representative of three separate experiments.

in mechano-transduction in osteoblast $(21,24)$. More importantly, some research indicated that PKG II was related to proliferation and apoptosis in some cells. For example, Cook et al found that in cultured human prostate cells, PKG II agonist 8-pCPT-cGMP inhibited the proliferation induced by fetal calf serum (15). They also found that activation of PKG II could induce apoptosis of human prostate cells (14). The results from Swartling's laboratory (18) and our laboratory (20) confirmed the proliferation-inhibitory effect of PKG II, suggesting that PKG II may be a potential tumor suppressor.

To further investigate the role of PKG II in tumor suppression, we studied the effect of PKG II on EGF receptor (EGFR) triggered signal transduction of MAPK-mediated pathway. With a molecular weight of $170 \mathrm{kDa}$, EGFR exists on the surface of all cells and has an extracellular domain, a cross-membrane domain and an intracellular domain. The intracellular domain of EGFR has 542 amino-acid residues and can be divided into the approximate membrane sub-domain, tyrosine kinase sub-domain, and C-terminal sub-domain (25). The activation of EGFR can trigger several signal transduction pathways and MAPK-mediated pathway is one of them (26). EGFR can recruit adapter protein Grb2 to its phosphorylated C-terminal and promote the binding between Grb2 and Sos1, when EGFR is activated (27). The activated Sos1 can then induce the change of small G protein Ras from GDP-bound form to GTP-bound form. The subsequent events after Ras activation in the signal transduction process include the activation of MEK, the activation of MAPK/ERK, and the activation of transcription factors and related enzymes. Our results revealed that PKG II inhibited the EGF induced activation of main signal transduction components in the pathway, including the binding between adapter protein Grb2 and Sos1, the activation of small $\mathrm{G}$ protein Ras, the phosphorylation/activation of MEK1/2, the phosphorylation/activation of MAPK/ERK, and the nuclear translocation of activated ERK. This systemically confirmed the inhibition of PKG II on EGFR triggered MAPK-mediated signal transduction pathway and provided conclusive evidence that PKG II inhibited the proliferation of gastric cancer cells through blocking the transduction of proliferative signaling.

Of note, our results revealed that PKG II inhibited the signal transduction through blocking the activation of EGF receptor, the initial event of the signal transduction process. This provides several hints for further investigation. Firstly, for the mechanism through which PKG II inhibited the signal transduction. Research data showed that serine/threonine in the approximate membrane sub-domain of EGFR can be phosphorylated and the phosphorylation had inhibitory effect on the activation of EGFR. For example, protein kinase $\mathrm{C}$ (PKC) and MAPK/ERK can phosphorylate the Thr 654 in the approximate membrane sub-domain to decrease the affinity of EGFR with its ligands and inhibit the activation of tyrosine kinase caused by the binding between EGFR and its ligands (25). Since PKG II is also a serine/threonine kinase, whether it blocks the activation of EGFR through similar mechanism needs further study. Therefore, the potential phosphorylation of serine or threonine on EGFR caused by PKG II will be our next research target.

Secondly, activation of EGFR can start the signal transduction of several pathways, including MAPK/ERK pathway, PI3K/Akt pathway, PLC $\gamma 1 /$ IP3/DAG pathway, and JAK1/STAT pathway (28-30). The signal transduction of these pathways is related not only to proliferation, but also to apoptosis and motility/migration of the cells. Does PKG II also inhibit the signal transduction of other pathways except MAPK pathway and affect other cellular activities except proliferation? This also needs further study. 
Thirdly, EGFR is closely associated with tumorigenesis. Overexpression and mutation of EGFR often occur in most cancers (31). Furthermore, cancer patients with overexpression of EGFR usually have poor prognosis. For example, EGFR overexpression was detected in $60 \%$ of non-small cell lung cancer (NSCLC) patients and the prognosis of the patients were poor, with a survival of 4-5 months (32). In vitro experiments confirmed that overexpression of EGFR caused transformation of NIH-3T3, Rat-1 and NRK cells and blocking EGFR activation inhibited proliferation of some tumor cells (33). Therefore, EGFR is the first growth factor receptor taken as cancer therapy target. Several methods of inhibiting EGFR activity and related signal transduction, including specific antibodies against EGFR and inhibitors of EGFR, have been studied in detail (34). New and more effective methods in blocking EGFR-mediated signal transduction will be helpful in cancer therapy. Our results show that PKG II can inhibit the activation of EGFR and the consequent signal transduction. This will provide new hints on strategy of cancer therapy.

\section{Acknowledgements}

This study was supported by the National Natural Science Foundation of China, No. 31040002 and No. 81001100; the Innovation Grant of Jiangsu University. We thank Dr Gerry Boss and Dr Renate Pilz, University of California, San Diego, CA, USA, for the kind gifts of adenoviral constructs.

\section{References}

1. Orstavik S, Natarajan V, Tasken K, Jahnsen T and Sandberg M: Characterization of the human gene encoding the type I alpha and type I beta cGMP-dependent protein kinase (PRKG1). Genomics 42: 311-318, 1997.

2. Orstavik S, Solberg R, Tasken K, et al: Molecular cloning, cDNA structure, and chromosomal localization of the human type II cGMP-dependent protein kinase. Biochem Biophys Res Commun 220: 759-765, 1996.

3. Shimojo T, Hiroe M, Ishiyama S, Ito H, Nishikawa $\mathrm{T}$ and Marumo F: Nitric oxide induces apoptotic death of cardiomyocytes via a cyclic-GMP-dependent pathway. Exp Cell Res 247: 38-47, 1999.

4. Segawa K, Minami K, Shiga Y, et al: Inhibitory effects of nicorandil on rat mesangial cell proliferation via the protein kinase $\mathrm{G}$ pathway. Nephron 87: 263-268, 2001.

5. Loweth AC, Williams GT, Scarpello JH and Morgan NG: Evidence for the involvement of cGMP and protein kinase $\mathrm{G}$ in nitric oxide-induced apoptosis in the pancreatic B-cell line, HIT-T15. FEBS Lett 400: 285-288, 1997.

6. Brunetti M, Mascetra N, Manarini S, et al: Inhibition of cGMP-dependent protein kinases potently decreases neutrophil spontaneous apoptosis. Biochem Biophys Res Commun 297: 498-501, 2002.

7. Haanen C: Sulindac and its derivatives: a novel class of anticancer agents. Curr Opin Investig Drugs 2: 677-683, 2001.

8. Liu L, Li H, Underwood T, et al: Cyclic GMP-dependent protein kinase activation and induction by exisulind and CP461 in colon tumor cells. J Pharmacol Exp Ther 299: 583-592, 2001.

9. Hou Y, Gupta N, Schoenlein P, et al: An anti-tumor role for cGMP-dependent protein kinase. Cancer Lett 240: 60-68, 2006.

10. Lincoln TM, Dey N and Sellak H: Invited review: cGMPdependent protein kinase signaling mechanisms in smooth muscle: from the regulation of tone to gene expression. J Appl Physiol 91: 1421-1430, 2001.

11. Gamm DM, Francis SH, Angelotti TP, Corbin JD and Uhler MD The type II isoform of cGMP-dependent protein kinase is dimeric and possesses regulatory and catalytic properties distinct from the type I isoforms. J Biol Chem 270: 27380-27388, 1995.
12. Vaandrager AB, Edixhoven M, Bot AG, et al: Endogenous type II cGMP-dependent protein kinase exists as a dimer in membranes and can Be functionally distinguished from the type I isoforms. J Biol Chem 272: 11816-11823, 1997.

13. Hofmann F: The biology of cyclic GMP-dependent protein kinases. J Biol Chem 280: 1-4, 2005.

14. Cook AL and Haynes JM: Protein kinase G II-mediated proliferative effects in human cultured prostatic stromal cells. Cell Signal 16: 253-261, 2004.

15. Cook AL and Haynes JM: Phosphorylation of the PKG substrate, vasodilator-stimulated phosphoprotein (VASP), in human cultured prostatic stromal cells. Nitric Oxide 16: 10-17, 2007.

16. Chiche JD, Schlutsmeyer SM, Bloch DB, et al: Adenovirusmediated gene transfer of cGMP-dependent protein kinase increases the sensitivity of cultured vascular smooth muscle cells to the antiproliferative and pro-apoptotic effects of nitric oxide/ cGMP. J Biol Chem 273: 34263-34271, 1998.

17. Hood J and Granger HJ: Protein kinase G mediates vascular endothelial growth factor-induced Raf-1 activation and proliferation in human endothelial cells. J Biol Chem 273: 23504-23508, 1998.

18. Swartling FJ, Ferletta M, Kastemar M, Weiss WA and Westermark B: Cyclic GMP-dependent protein kinase II inhibits cell proliferation, Sox 9 expression and Akt phosphorylation in human glioma cell lines. Oncogene 28: 3121-3131, 2009.

19. Yang SQ, Chen YC, Wang Y and Tao Y: Expression of cGMP dependent protein kinase II in cancer cell lines was obviously decreased. J Jiangsu Univ 18: 1-5, 2008.

20. Chen YC, Ren F, Sang JR, Tao Y and Xu WR: Type II cGMPdependent protein kinase inhibits proliferation of the gastric cancer cell line BGC-823. Mol Med Rep 3: 361-366, 2010.

21. Rangaswami H, Marathe N, Zhuang S, et al: Type II cGMP-dependent protein kinase mediates osteoblast mechanotransduction. J Biol Chem 284: 14796-14808, 2009.

22. Chen JC,Zhuang S, Nguyen TH, Boss GR and Pilz RB: Oncogenic Ras leads to Rho activation by activating the mitogen-activated protein kinase pathway and decreasing Rho-GTPase-activating protein activity. J Biol Chem 278: 2807-2818, 2003.

23. Ren XD, Kiosses WB and Schwartz MA: Regulation of the small GTP-binding protein Rho by cell adhesion and the cytoskeleton. EMBO J 18: 578-585, 1999.

24. Rangaswami H, Schwappacher R, Marathe N, et al: Cyclic GMP and protein kinase $\mathrm{G}$ control a Src-containing mechanosome in osteoblasts. Sci Signal 3: ra91, 2010.

25. Wells A: EGF receptor. Int J Biochem Cell Biol 31: 637-643, 1999.

26. Jiang H, Grenley MO, Bravo MJ, Blumhagen RZ and Edgar BA: EGFR/Ras/MAPK signaling mediates adult midgut epithelial homeostasis and regeneration in Drosophila. Cell Stem Cell 8: 84-95, 2011.

27. Yamazaki T, Zaal K, Hailey D, Presley J, Lippincott-Schwartz J and Samelson LE: Role of Grb2 in EGF-stimulated EGFR internalization. J Cell Sci 115: 1791-1802, 2002.

28. Hwang YP, Yun HJ, Choi JH, et al: Suppression of EGF-induced tumor cell migration and matrix metalloproteinase-9 expression by capsaicin via the inhibition of EGFR-mediated FAK/Akt, PKC/Raf/ERK, p38 MAPK, and AP-1 signaling. Mol Nutr Food Res 55: 594-605, 2011.

29. Katterle Y, Brandt BH, Dowdy SF, Niggemann B, Zanker KS and Dittmar T: Antitumour effects of PLC-gamma1-(SH2)2-TAT fusion proteins on EGFR/c-erbB-2-positive breast cancer cells. Br J Cancer 90: 230-235, 2004.

30. Quesnelle KM, Boehm AL and Grandis JR: STAT-mediated EGFR signaling in cancer. J Cell Biochem 102: 311-319, 2007.

31. Normanno N, Bianco C, De Luca A, Maiello MR and Salomon DS: Target-based agents against ErbB receptors and their ligands: a novel approach to cancer treatment. Endocr Relat Cancer 10: 1-21, 2003.

32. Sharma SV, Bell DW, Settleman J and Haber DA: Epidermal growth factor receptor mutations in lung cancer. Nat Rev Cancer 7: 169-181, 2007.

33. Hu T and Li C: Convergence between Wnt- $\beta$-catenin and EGFR signaling in cancer. Mol Cancer 9: 236, 2010.

34. Quatrale AE, Porcelli L, Silvestris N, Colucci G, Angelo A and Azzariti A: EGFR tyrosine kinases inhibitors in cancer treatment: in vitro and in vivo evidence. Front Biosci 16: 1962-1972, 2011. 